\title{
Comunidades negras no Ceará: da invisibilidade à formação dos quilombos contemporâneos
}

\section{Black communities in Ceará: from invisibility to the formation of contemporary quilombos}

Leilane Oliveira Chaves - Mestre em Desenvolvimento e Meio Ambiente - Doutoranda bolsista Capes do Programa de Pós-graduação em Desenvolvimento e Meio Ambiente da Universidade Federal do Ceará. E-mail: leilane_chaves@hotmail.com

Edson Vicente da Silva - Doutor em Geografia - Professor Titular do Departamento de Geografia da Universidade Federal do Ceará. E-mail: cacauceara@gmail.com

\section{Resumo}

As comunidades quilombolas obtiveram maior visibilidade face às reivindicações de diversos segmentos sociais e principalmente do envolvimento dos quilombolas pelo direito de se autodefinirem. Esses grupos formaram-se a partir do século XVI, como forma de resistência às condições de vida e de trabalho. No presente, compreendem diferentes contextos de posse de terras por populações predominantemente negras ou de seus descendentes no país. Desta forma, buscase analisar o discurso da invisibilidade da presença negra no estado do Ceará frente ao reconhecimento de comunidades quilombolas contemporâneas. A pesquisa efetivada ancorou-se em levantamentos bibliográficos, conhecimentos empíricos, censos populacionais e instrumentos legais reunindo considerações sobre os principais conflitos que permeiam a autodefinição desses grupos. Acredita-se que o trabalho é uma importante contribuição para a visibilidade do movimento quilombola cearense.

\section{Palavras-chave}

Comunidades Quilombolas. Ceará. Invisibilidade Social. Conflitos Sociais.

\begin{abstract}
The quilombo communities have gained greater visibility in face of the claims of diverse social segments and especially the involvement of quilombolas for the right of self define. These groups were formed from the sixteenth century as a form of resistance to living and working conditions. At present, they comprise different land tenure contexts by predominantly black populations or their descendants in the country. Thus, it is sought to analyze the discourse of the invisibility of the black presence in the State of Ceará in face of the recognition of contemporary quilombo communities. The research was carried out based on bibliographic surveys, empirical knowledge, population census and legal instruments, thus gathering considerations about the main conflicts that permeate the self definition of these groups. it is believed that this work is an important contribution to the visibility of Cearás quilombo movement.
\end{abstract}

\section{Keywords}

Quilombo Comunities. Ceará. Social

Invisibility. Social Conflicts. 


\section{INTRODUÇÃO}

As comunidades quilombolas contemporâneas, a partir da mobilização de diferentes setores da sociedade inauguram um novo contexto nacional, saindo da invisibilidade em direção ao reconhecimento proporcionando a garantia de direitos legais das terras tradicionalmente ocupadas permitindo a manutenção de suas formas de vida. Com a visibilidade desses grupos criou-se uma nova demanda social, a regularização dos territórios quilombolas acirrando discussões e acarretando na inserção de novos elementos de análise territorial, como o uso dos recursos naturais para a subsistência desses grupos e melhorias nas condições de saúde, educação, trabalho, dentre outros serviços e direitos para a população quilombola.

No Brasil, já foram identificadas cerca de 2 mil comunidades quilombolas rurais, urbanas e periurbanas em diversas regiões. No estado do Ceará, em decorrência da afirmação da inexistência do negro ainda no período colonial, esses grupos, também denominados de comunidades negras rurais, até recentemente encontravam-se no anonimato. Com o passar dos anos e em virtude do posicionamento do movimento negro cearense, das comunidades negras e da sociedade civil, possibilitou-se a inserção de novos elementos na historiografia cearense, destacando a importância desses grupos na formação da identidade local.

Os procedimentos de titulação desses territórios é um dos maiores elementos geradores de discussões. No estado do Ceará, não é diferente, pois esta é uma questão presente em todos os territórios do Brasil. Outro tema que merece atenção, e que tem dificultado a autodefinição desses grupos, é a compreensão da presença das comunidades quilombolas na atualidade, não só por parte da sociedade civil, mas por instituições públicas municipais e estaduais. Na ausência desse entendimento, o que se observa, é a omissão de direitos, casos crescentes de violência, por meio de ameaças de morte e desestruturação das lideranças, comprometendo a permanência nos espaços coletivos tradicionalmente utilizados pelas populações locais.

Outro elemento que tem sido motivador de interesses divergentes é a garantia quanto ao uso dos recursos naturais, estes são limitados tanto pelos grileiros que afirmam deter os títulos da terra, como pelo poder público por meio da legislação ambiental. Muitas práticas utilizadas cotidianamente por essas comunidades têm sido consideradas ilegais, como o extrativismo vegetal com a retirada da madeira, empreendida na construção das residências e de benfeitorias nas propriedades. 
Para Almeida (2004), as terras ocupadas pelas comunidades quilombolas cumprem importante função social, pois por meio da organização comunitária esses grupos gerenciam os recursos naturais, garantindo a sua reprodução biológica e cultural. A posse coletiva favorece a família, a comunidade e a própria configuração étnica como um todo.

Nessa perspectiva, pretende-se com o presente artigo realizar uma análise e reflexão sobre o período de invisibilidade negra e seu posterior afloramento na concepção dos novos quilombos. Serão destacados os conflitos territoriais presentes nas comunidades quilombolas cearenses, envolvendo diferentes atores e interesses na apropriação e uso dos recursos naturais.

Essa reflexão baseia-se em levantamentos bibliográficos, em análise empírica e em discussões que norteiam os instrumentos legais que garantem o direito desses grupos. Assim, reuniram-se considerações amplas, mas que substanciassem os principais conflitos que permeiam a garantia dos direitos das comunidades quilombolas no estado, aprofundando a investigação no que diz respeito ao papel dos africanos escravizados na formação da sociedade cearense, a invisibilidade dos negros na historiografia local e a formação de quilombos contemporâneos.

\section{CENÁRIO ATUAL DAS COMUNIDADES QUILOMBOLAS NO BRASIL}

Assim como os índios, os africanos não aceitaram passivamente o trabalho escravo, existindo cotidianamente diversas formas de resistência, tanto individual como coletiva. "Fugindo o escravo demonstrava sua fibra rebelde, o calor de sua revolta, indiferente aos impiedosos castigos a que seria submetido quando capturado: açoites, tronco, ferro em brasa, colares de ferro, e até amputação se reincidente [...]" (GOULART, 1972, p. 28).

Algumas fugas resultaram na formação de comunidades independentes, que mais tarde receberam o nome de quilombos. Esses grupos existiram desde a época colonial até os últimos anos do sistema escravista. Moura (1981) assinala que os quilombos eram considerados um fenômeno não circunscrito a uma região específica, mas que pontilharam diversas partes do território brasileiro. A historiografia nacional relata que estes obtiveram diferentes tipos de formação, há quilombos com resistência à escravidão, há quilombos criados com a compra da terra pelos negros, há quilombos instituídos por negros livres desde a ocupação das terras pós-abolição. 
Na primeira metade do século XIX após a formulação de leis e tratados entre Portugal e Inglaterra sobre o fim do tráfico negreiro, surge a figura do africano livre. Considerado livre, porém não emancipado. Muitos escravos continuaram sendo tratados como cativos e suas condições de trabalho, moradia e alimentação se assemelhavam aos vividos no período da escravidão. O Brasil foi uma das últimas nações americana a acabar com a escravidão, entretanto esse regime de trabalho vigorou em território nacional por mais de 300 anos, haja vista que, o sistema econômico vigente durante os períodos colonial e imperial tinham como base a mão de obra escrava (FIABANI, 2008).

Muitos africanos e seus descendentes, mesmo após a abolição, preferiram continuar residindo nas comunidades de negros rurais, constituídas ainda no Período Colonial. Outros continuaram nas fazendas na condição de parceiros na produção agrícola. Ainda existiam aqueles antigos cativos que receberam terrenos de seus senhores mediante doações ou compras de pequenos lotes. Muitas dessas áreas, como ressalta Fiabani (2008), tornaram-se referência para aglomeração dos escravos livres. Na maioria das vezes, a terra era de uso coletivo, dificultando a divisão da propriedade e contribuindo para a permanência desses grupos de forma coletiva.

Graças à sua organização, os quilombos estabeleceram alianças não só com outros fugitivos, mas também com grupos indígenas, pequenos agricultores e comerciantes que contribuíam para a comercialização dos produtos agrícolas e para a manutenção desses grupos até a contemporaneidade (MATTOS, 2007).

Após o ato abolicionista, os quilombos juridicamente deixaram de existir, e até pensou-se que, com o fim da escravidão, estes grupos haviam sido diluídos socialmente. Uma vez que este segmento social não despertou interesse nem de pesquisadores e autoridades de épocas passadas, ficou invisível por um longo período. Nas décadas de 1970 e 1980, timidamente, se iniciaram os primeiros estudos acadêmicos, identificando a existência desses grupos, mas foi após a Constituição de 1988 que adquiriram uma visão pública da sua realidade nacional, desvendandose as reais condições das comunidades negras rurais (FIABANI, 2008).

Assim, com a promulgação da Constituição Federal em 1988, cujo artigo 68 do Ato das Disposições Constitucionais Transitórias (ADCT), prevê o reconhecimento da propriedade das terras aos "remanescentes das comunidades de quilombos", o debate ganha o cenário político nacional, resultando em publicações das mais diversas.

Esse reconhecimento é fortalecido com a consolidação das questões normativas nacionais, garantindo não só a titulação das terras tradicionalmente ocupadas, mas, principalmente, o direito de se identificar como pertencente a 
esse grupo. Na visão de Almeida (2004), a incorporação dessas reivindicações na legislação e nos aparatos burocráticos administrativos não significou um acatamento das suas solicitações e tão pouco na resolução dos conflitos em torno da apropriação e do uso dos recursos naturais.

$\mathrm{Na}$ atualidade esses territórios ainda são considerados espaços de interesses divergentes, implicando na coação e benefícios de outros atores sociais, comprometendo a base de sustento desses grupos, a julgar que a garantia da terra é um elemento fundamental para a manutenção das condições de vida dessas populações. Essas comunidades desenvolveram práticas de convivência com os diferentes ambientes naturais, contribuindo para manutenção da biodiversidade (INCRA, 2012).

Segundo dados do Instituto de Colonização e Reforma Agrária (INCRA), em conjunto com a Fundação Cultural Palmares (FCP) e a Secretária de Políticas de Promoção da Igualdade Racial (SEPPIR), no Brasil, somam-se mais de 3.500 comunidades quilombolas identificadas, destas, 1.200 já receberam a certidão de identificação junto à FCP e emitiram-se 154 títulos em 127 territórios, beneficiando 13.145 famílias distribuídas em diferentes estados da federação (INCRA, 2012).

No presente, infelizmente, quando transferidos para o processo de titulação, esses dados decaem vertiginosamente. A região Norte apresenta os maiores índices de territórios titulados, com 59 títulos, seguidas das regiões Nordeste com 49, Sudeste 10, Centro-Oeste 6 e Sul com 3 títulos. Dentre os estados da federação, o Pará se destaca com 55 títulos, seguidos pelo Maranhão com 33, São Paulo 6 e Bahia e Piauí, com 5 territórios cada. Esses números anualmente passam por modificações à medida que esses grupos se autoidentificam, como assegura o Decreto 4.887/03 (BRASIL, 2003).

A região Nordeste, há 49 territórios titulados, beneficiando 5.123 famílias, com destaque para o Maranhão com 2.173 e Bahia com 1.012 famílias beneficiadas. O estado do Ceará, foco do presente artigo, é composto por 184 municípios, dos quais 33 já identificaram em seu perímetro territorial a existência de comunidades quilombolas, desde 2004.

Nos últimos anos essas comunidades adquiriram maior visibilidade junto ao poder público e à sociedade civil, por intermédio da realização de inventários e de mapeamentos. Esses levantamentos vêm sendo realizados por meio de parceria das comunidades com a Comissão Estadual de Comunidades Negras Rurais do Ceará (CEQUIRCE). Essa interação possibilitou uma maior notoriedade desses grupos junto à sociedade civil, principalmente em decorrência do cenário étnicoracial do Ceará que sempre negou a presença do negro em seu território. 
É importante evidenciar, que há hoje, um novo cenário no estado do Ceará, principalmente em decorrência da tentativa de promover a desmistificação do mito da hegemonia de uma sociedade formada exclusivamente por uma população branca. Assim, almeja-se transpor o bloqueio da invisibilidade do negro no estado, para assumir garantia dos direitos dos quilombolas conquistados ao longo dos últimos vinte anos.

\section{A PRESENÇA NEGRA NO CEARÁ}

Conflitos sociais no campo não representou exclusividade de nossos tempos, mas sim uma marca do desenvolvimento e do processo de ocupação do campo no país; os grupos indígenas foram os primeiros a conhecer a avidez de terra por parte dos colonizadores. Simultaneamente à luta dos indígenas, nasceu a

peleja dos negros escravizados contra as formas de trabalho empreendidas pelos portugueses (OLIVEIRA, 1989).

A origem do elemento servil negro no Ceará surge da consolidação da ocupação da capitania, acentuando-se quando esta se torna autônoma da capitania de Pernambuco, estando livre para poder comercializar diretamente com a Metrópole (PINHEIRO, 2004). A ocupação das terras cearenses deu-se com suas fronteiras sendo rompidas pelo gado, diferenciando-se do processo ocorrido em outras áreas do Nordeste açucareiro. Caracterizado por um processo mais lento e com pouca mão-de-obra negra escravizada, contando desde o início com a força de trabalho do nativo (FUNES, 2004).

Funes (2004) esclarece que a ocupação foi se efetivando inicialmente como espaço de trabalho, atraindo um contingente de homens livres, negros e pardos, em sua maioria pobres que se deslocavam das províncias vizinhas para desempenhar atividades de vaqueiros, agricultores ou como moradores e agregados das fazendas. No segundo momento, com a crescente produção da lavoura algodoeira, ainda no século XVIII, acentuou-se uma demanda por mãode-obra, tanto livre como negra escravizada.

Neste período a quantidade de negros e pardos cativos era bastante expressiva, tendo nas vilas de Sobral (2.978), S. João Príncipe (1.856), Campo Maior (1.270) e Icó (1.507), as maiores representatividades. Mesmo com altos índices para a região, se comparada a outras localidades, a capitania do Ceará mostrou pouca expressão em quantidade de africanos, haja vista que as atividades desenvolvidas, como a pecuária e a agricultura de subsistência não demandavam um número expressivo de mão-de-obra escrava de origem africana, o que não significava a inexistência de tais grupos, como durante muito tempo foi considerado. 
Sousa (2008) manifesta a ideia de que a origem desse mito está ligada diretamente à historiografia tradicional cearense, tendo no Instituto Histórico, Geográfico e Antropológico do Ceará o seu principal legitimador. As formas como essas ideias se tornaram hegemônicas na sociedade cearense pautase na credibilidade que a instituição adquiriu naquele período. Esta era a mais importante fonte para a pesquisa histórica local, tornando-se ao longo dos anos uma referência como centro de informação histórica e geográfica. Os membros do Instituto do Ceará, ao dissertarem sobre o pioneirismo cearense no processo da abolição, enfatizaram a escala reduzida e sem grandes influências socioculturais dos africanos e seus descendentes na sociedade cearense.

Entretanto, é importante evidenciar que, assim como em outras capitanias, a mão-de-obra escrava, mesmo em quantidade inferior às existentes em outras capitanias, fez-se presente em todo o campo de trabalho, tanto no espaço rural como no urbano. Sua força de trabalho era utilizada na pecuária, na agricultura, em serviços domésticos especializados e ainda como escravos de aluguel ou de ganho.

Em termos culturais, as manifestações dos negros foram sistematicamente combatidas. Sousa (2008) esclarece que, na visão das autoridades e da sociedade de uma forma geral, essas lembranças faziam do negro uma ameaça permanente à ordem, proibindo cotidianamente seus rituais religiosos, cantorias e danças. Muitas dessas manifestações, ao longo do século XX, foram extintas e outras praticamente perderam o referencial histórico.

Ainda abordando a representatividade desses grupos, Ratts (2009) enfatiza que, em 1808, o Ceará já contava com uma população de 125.878 habitantes, sendo que desse total 19\% eram pretos, 37\% eram mulatos, 10\% eram índios e $34 \%$ eram brancos.

No século XIX, na década de 1840, a entrada de escravos na capitania do Ceará já era praticamente inexistente, em especial decorrente das primeiras proibições do tráfico negreiro. Em 1850, o Ceará passou a exportar negros cativos dentro do processo de tráfico interprovincial. Em 1883, às vésperas da extinção da escravidão no Ceará, a população cativa já demonstrava queda acentuada (FUNES, 2004).

A abolição da escravidão no Ceará permite ao cativo recuperar sua liberdade, mas vem acompanhada de uma série de medidas restritivas que mantém essa pessoa em situação inferior, excluindo-o da possibilidade de ascensão social e de direitos à cidadania. É o momento em que o negro vê legitimar sua exclusão social. É-lhe concedida à liberdade, mas nega-se o direito à cidadania. “[...] Excluído vai-se aquilombando nas periferias, nas favelas, nas frentes de expansão, 
enclausurando-se no seu mundo rural, no seu universo cultural, constituindo a sua identidade, a partir de sua historicidade" (FUNES, 2004, p. 132).

Em momentos como esse é que se percebe como os cativos escravizados e posteriormente, negros libertos são postos à margem da sociedade, fazendo desaparecer do processo histórico cearense as etnias negras e indígenas (FUNES, 2004).

O negro no Ceará até o início dos anos 1980 estava subjugado a um discurso por demais estigmatizante, ressaltando sua presença de pouca recorrência e relevância social (SOUSA, 2008). "Nesse sentido, no Ceará, a abolição precoce do elemento servil, em franco declínio a partir do final da década de 1870, decretou a "invisibilidade" do negro cearense muito mais do que a abolição da exploração escravocrata” (RIBARD, 2009, p. 97).

$\mathrm{O}$ esforço de reafirmar tal invisibilidade por parte de alguns setores da sociedade a partir do século XXI começa a sofrer alterações, principalmente, em decorrência do movimento criado pelas próprias comunidades negras na busca de reconhecimento e direitos.

\section{ONDE ESTÃO E COMO VIVEM OS QUILOMBOLAS DO CEARÁ?}

O estado do Ceará esta situado na região Nordeste e tem por limites o oceano Atlântico a norte e nordeste, Rio Grande do Norte e Paraíba a leste, Pernambuco a sul e Piauí a oeste. Sua área é de 148.825,6 km², correspondendo a 9,37\% da área do Nordeste Brasileiro e 1,7\% da superfície do território nacional (IBGE, 2011). Como em outras regiões tem em suas origens históricas a presença indígena, europeia e africana, sendo esta última empregada na lavoura de canade-açúcar, do café e da banana.

As primeiras análises dos quilombos, além de sua visão como prática criminal, datam do século XX. Ainda assim, a percepção de sua formação baseada em selvagens continuou perdurando, mas, de certa forma, estimulando pesquisadores a aprofundarem suas compreensões acerca desses grupos, não mais como bárbaros, mas sim pela óptica da resistência (CALLHEIROS; STADTLER, 2010).

Atualmente, o que conceitua essas comunidades vai além de sua formação com a fuga, buscando compreender o seu significado, abarcando os vários contextos de posse de terras por comunidades negras no País. A razão disso é que os quilombolas se definem com suporte nas suas relações com a terra, o parentesco, as tradições, as práticas culturais, dentre outros. Na visão de Schmitt, Turatti e Carvalho (2002), essa diversidade de manifestações é compreendida no 
partilhamento do território e de uma identidade e constituída sempre em relação aos outros grupos com os quais os quilombolas se relacionam.

O’Dwyer (2010) salienta que o termo quilombo refere "sobretudo, a grupos que desenvolveram práticas cotidianas de resistência na manutenção e reprodução de seus modos de vida característicos e na consolidação de um território próprio". Ainda segundo a autora, as formas de ocupação da terra não ocorrem de forma individual, predominando o uso comum e de acordo com a sazonalidade das atividades desenvolvidas, sejam elas, agrícolas, extrativistas ou quaisquer outras, tomando por base laços de parentesco e vizinhança.

Os quilombos contemporâneos espalhados por diversas localidades demonstram a representatividade que a presença africana logrou em território cearense. A manifestação de sua existência despertou para o reconhecimento de suas lutas e de suas formas de resistência no processo de formação da sociedade, "[...] que atravessaram o período colonial e imperial e que abalaram a estrutura econômica escravocrata no abolicionismo negro" (SOUSA, 2008, p. 36).

No presente, o estado do Ceará conta com 75 comunidades quilombolas, das quais 38 já possuem registro no Cadastro Geral da FCP. Ainda constam comunidades que estão em decurso de identificação, como o Quilombo da Serra dos Bastiões, município de Iracema, e comunidades que já passaram por esse momento e estão aguardando a emissão da certidão junto à FCP, sendo que ao todo são 10 (Domingos Pereira, Vila Nova, Barriguda, Batoque, Sítio Carcará, Cajueiro dos Lira, Cipoeiro, Olho d'Água, Nossa Senhora das Graças do Sítio Arapuca e Sítio Carnaúba). Além dessas comunidades que já estabeleceram algum tipo de relação com os órgãos federais, estaduais e municipais, a CEQUIRCE desenvolveu, de forma paralela, trabalhos de autodefinição com comunidades que não deram entrada junto à FCP, mas já iniciaram internamente o processo de autodefinição.

A CEQUIRCE expressa que existem 27 comunidades em decurso de identificação. Essas comunidades estão localizadas nos municípios de Araripe (2), Aurora (1), Mauriti (1), Potengi (2), Aquiraz (1), Salitre (1), São Benedito (1), Caucaia (4), Aracati (1), Milhã (2), Independência (1), Ipueiras (1), Novo Oriente (3), Parambu (4), Poranga (1) e Tamboril (1). E em dezembro de 2013 foi decretada a emissão dos títulos de propriedade, beneficiando quatro comunidades (Sítio Arruda em Araripe, Encantados do Bom Jardim e Lagoa das Pedras em Tamboril e Alto Alegre em Horizonte).

As comunidades, em sua maioria, localizam-se em áreas de difícil acesso e em condições precárias de vida. Apesar dessa fragilidade, os territórios quilombolas se estabeleceram ao longo do tempo, existindo quilombos com mais 
de 200 anos de fixação na mesma localidade. Estes criam e recriam suas formas de vida, se adaptam à natureza e à realidade que os cercam.

Esses quilombos distribuem-se geograficamente em diversas paisagens, habitando desde áreas elevadas até a depressão sertaneja assegurando formas diferenciadas de uso e ocupação do solo. A ocupação de áreas diversificadas garantiu uma diversidade cultural a essas comunidades, permitindo traçar diferentes formas de convivência com esses ambientes.

A formação de quilombos, a partir da fuga e ocupação de áreas distantes, foi bastante comum em diversas regiões do Brasil. Contudo, as condições de vida nesses sistemas ambientais se assemelham. Pressões externas, ausência de serviços básicos como agentes de saúde, educação, transporte, saneamento básico, apoio técnico ao pequeno agricultor são problemas comuns a várias comunidades.

Essa condição não é recente, pois mesmo após a abolição, as condições de vida e, principalmente, de trabalho, não foram modificadas. Fugiu da condição de escravo, mas não era totalmente livre.

Essas comunidades quilombolas não possuem documentação de posse ou propriedade da terra. Muitas delas foram cedidas pelos atuais posseiros há bastante tempo, sendo que algumas estabeleceram relações de arrendamento com os "donos" das terras. Essa prática é muito comum nas áreas rurais, onde os pequenos produtores, os arrendatários, conseguem a concessão de uma parte da propriedade agrícola, comprometendo-se, independentemente de seus rendimentos, ao pagamento, que pode ser em espécie ou em produtos, sobre seu uso.

As práticas produtivas predominantes como agricultura, extrativismo e criação de pequenos animais é a base de sustento desses grupos. Há ainda comunidades que desenvolvem artesanato e criação de peixes em tanques, mas em menor escala. Praticamente tudo o que é cultivado abastece a família e quando ocorre um excedente este é trocado ou vendido no comércio local. As residências são predominantemente de taipa e foram construídas em conjunto pelo núcleo familiar.

De acordo com o último censo realizado pelo INCRA, o estado possui em alguns de seus municípios mais de uma comunidade quilombola, como pode ser visto em Caucaia (5), Quiterianópolis (5), Tamboril (4), Salitre (2), Ipueiras (2), Monsenhor Tabosa (2), Novo Oriente (2) e Tururu (2) (INCRA, 2012).

Mesmo diante de tantos processos de autodefinição, o caminho percorrido pelo movimento quilombola cearense ainda é recente. As ideias proclamadas dão pouca expressividade a esses grupos no estado do Ceará, e fizeram com que muitas comunidades negras rurais protelassem os seus processos de identificação como quilombolas. Além disso, os conflitos advindos da questão fundiária 
também complementam esse retardamento.

Ratts (2009), ao abordar a atual conjuntura do movimento quilombola no Ceará, identifica que se encontram nessas comunidades moradores que se mantêm como agricultores e trabalhadores rurais. E que, apesar da afirmação de que no Ceará não existiam negros, essa visão passou a ser modificada a partir dos anos de 1970, com as primeiras identificações de comunidades negras rurais, e, em 1980, com a emergência do movimento negro e posterior fundação do Grupo União e Consciência Negra (GRUCON) no bairro Jardim Iracema, na cidade de Fortaleza (SOUSA, 2008).

A redescoberta dos quilombos permitiu ao movimento negro cearense realizar levantamentos e proposições de um panorama das reais condições dos moradores dessas comunidades, não só em relação aos aspectos de sua identidade, mas, também, quanto às formas de organização e condições de vida. Ainda em 1992 com a realização do Fórum de Entidades Negras do Ceará foi possível realizar um levantamento com 50 localidades com populações afrodescendentes distribuídas em todo o estado (RATTS, 2009).

Essa constante busca por legitimidade e representatividade possibilitou o despertar para uma maior organização das comunidades quilombolas contemporâneas e o início para a elaboração das comissões no plano estadual. A Comissão Estadual de Comunidades Quilombolas Rurais do Ceará (CEQUIRCE), criada em 2006, é a responsável pela articulação estadual das comunidades, possibilitando a inclusão nas discussões nacionais das particularidades pertinentes às comunidades localizadas no território.

A CEQUIRCE é uma entidade de fundamental importância na gestão dos conflitos existentes nas áreas ocupadas pelas comunidades quilombolas, não só em relação à titulação das terras, mas nas formas de uso dos recursos naturais, base para a subsistência das comunidades. Muitas práticas cotidianas como o extrativismo vegetal e os cultivos dos roçados estão sendo constantemente objetos de críticas por parte dos órgãos ambientais, penalizando criminalmente atos tradicionais das comunidades quilombolas.

Hábitos como caçar, pescar, criar animais, limpar o terreno para os roçados, retirar a madeira para a construção das residências e para cozinhar, são essenciais para o desenvolvimento sociocultural dessas comunidades. No entanto, essas práticas são consideradas como infrações ambientais, podendo ser punidas criminalmente. Ao mesmo tempo são elaborados dispositivos legais como a Política Nacional de Desenvolvimento Sustentável dos Povos e Comunidades Tradicionais que garantem a reprodução plena de suas formas de vida. 
Essas divergências e limitações ocasionam o agravamento das precárias condições de vida, expulsão das populações tradicionais e, em alguns casos, ainda uma maior degradação ambiental, à medida que ocupam novas áreas. A criminalização dessas comunidades especializou-se em diversas comunidades no estado.

Nesse contexto, a realidade destas comunidades quilombolas no Ceará, hoje, ainda carece de informações sistematizadas que possam subsidiar políticas públicas que propiciem melhores condições de vida à população remanescente.

\section{CONSIDERAÇÕES FINAIS}

$\mathrm{Na}$ historiografia cearense, durante muito tempo, propagou-se a pouca expressividade da presença negra na sociedade. Essas afirmações contribuíram para a disseminação da invisibilidade legal do negro, seja ele cativo ou livre.

A busca por visibilidade permitiu inicialmente a distinção entre quilombos coloniais e contemporâneos, possibilitando a ressemantização desse conceito, além de colaborar para avanços na legislação brasileira, garantindo não só reconhecimento nacional, mas garantias quanto à permanência nas terras tradicionalmente ocupadas. Dentre os principais instrumentos jurídicos elaborados, destacam-se a Constituição de 1988, inserindo os quilombolas na luta por igualdade e cidadania e o Decreto 4.888/03, dando o direito a esses grupos à autodefinição.

Em conclusão, na atualidade as comunidades quilombolas cearenses ainda permanecem invisíveis aos olhos do poder público e da sociedade. O direito à terra e à reprodução de sua forma de vida têm sido negligenciados e muitas vezes silenciados. As informações levantadas aqui revelam a necessidade de valorizar e resguardar os conhecimentos e práticas tradicionais vivenciadas cotidianamente por essas comunidades.

As relações de poder historicamente estabelecidas, em muitas situações, inibem o poder público de cumprir a obrigação de regularizar e titular as terras ocupadas. A morosidade na conclusão desses processos é uma delas, mas dificuldades operacionais decorrentes da má utilização dos recursos orçamentários para este fim também tem sua contribuição. Além disso, a pressão que as comunidades estão expostas na luta pelo direito à terra, em algumas situações, compromete a finalização do processo de regularização fundiária. Assim, muitas vezes os interesses dos latifundiários se sobrepõem ao direito garantido por lei aos quilombolas. 


\section{REFERÊNCIAS}

ALMEIDA, A. W. B. de. Terras tradicionalmente ocupadas: processos de territorialização e movimentos sociais. R. B. Estudos Urbanos e Regionais, Rio de Janeiro, v. 6, n. 1, p. 9-32. 2004.

BRASIL, Constituição (1988). Constituição da República Federativa do Brasil. 27. ed. Brasília: Câmara dos Deputados, 2007.

. Decreto n⿳o 6.040, de 07 de fevereiro de 2007. Diário Oficial da União, Brasília, 08 de fevereiro de 2007, Seção 1, p. 316.

. Decreto $\mathrm{n}^{\mathrm{O}} 4.887$, de 20 de novembro de 2003. Diário Oficial da União, Brasília, 21 de novembro de 2003, Seção 1, p. 4.

CALLHEIROS, F. P.; STADLER, H. H. C. A identidade étnica e poder: os quilombos nas políticas públicas brasileiras. Rev. Katál, Florianópolis, v. 13, n. 1, p. 133-139, jan/jun. 2010.

FIABANI, A. Os novos quilombos: luta pela terra e afirmação étnica no Brasil (1988 - 2008), 2008. 275f. Tese (Doutorado em História) - Centro de Ciências Humanas, Universidade do Vale do Rio dos Sinos, São Leopoldo, 2008.

FUNES, E. A. Negros no Ceará. In: SOUZA, Simone de; GONÇALVES, Adelaide (Org.). Uma nova história do Ceará. Fortaleza: Demócrito Rocha, 2004. p. 103-13).

GOULART, J. A. Da fuga ao suicídio: aspectos de rebeldia dos escravos no Brasil. Rio de Janeiro: Conquista, INL, 1972.

IBGE. Cidades@: 2011. Disponível em: <http://www.ibge.com.br/cidadesat/ topwindow.htm?1>. Acesso em: 12 jan. 2016.

INCRA. Quilombolas. 2012. Disponível em <http://www.incra.gov.br/ estrutura-fundiaria/quilombolas >. Acesso em: 01 fev. 2016.

MATTOS, R. A. Histórico e cultura afro-brasileira. São Paulo: Contexto, 2007.

MOURA, C. Os quilombos e a rebelião negra. São Paulo: Brasiliense, 1981.

O'DWYER, E. C. Terras de quilombo no Brasil: direitos territoriais em construção. In: ALMEIDA, A. W. B. (Org.). Territórios quilombolas e conflitos. Manaus: UEA, 2010. p. 42-49. 
OLIVEIRA, A. U. de. A Geografia das lutas no campo. São Paulo: Contexto, 1989.

PINHEIRO, F. J. Mundos em Confrontos: povos nativos e europeus na disputa do território. In: SOUZA, S. de; GONÇALVES, A. et al. (Org.). Uma nova história do Ceará. Fortaleza: Demócrito Rocha, 2004. p. 17-55.

RATTS, A. Traços étnicos: espacialidades e culturas negras e indígenas. Fortaleza: Museu do Ceará/SECULT, 2009.

RIBARD, F. A corte real dos reis de congo: territórios festivos negros em trânsito (Fortaleza - 1871/1900). In: HOLANDA, C. R. (Org.). Negros no Ceará: história, memória e etnicidade. Fortaleza: Museu do Ceará/SECULT/Imopec, 2009. p. 95-110.

SCHMITT, A.; TURAT'TI, M. C. M.; CARVALHO, M. C. P. de. A atualização do conceito de quilombo: identidade e território nas definições teóricas. Ambiente \& Sociedade, São Paulo, v. 5, n. 10, p. 129-132, $1^{\text {o }}$ sem. 2002.

SOUSA, A. V. C. Afro-cearenses em construção: discursos identitários sobre o negro no Ceará. Fortaleza: Demócrito Rocha, 2008. 